\title{
A comunidade microfitoplanctônica do Arquipélago de São Pedro e São Paulo (Atlântico Norte-Equatorial): variação diurna e espacial
}

\author{
Andréa Shirley Xavier da Silva Tiburcio ${ }^{1,2}$, Maria Luise Koening ${ }^{1}$, \\ Silvio José de Macêdo ${ }^{1}$ \& Pedro Augusto Mendes de Castro Melo ${ }^{1}$ \\ ${ }^{1}$ Departamento de Oceanografia, Universidade Federal de Pernambuco - UFPE, \\ Av. Arquitetura, s/n, Cidade Universitária, CEP 50670-901, Recife, PE, Brasil \\ ${ }^{2}$ Autor para correspondência: Andréa Shirley Xavier da Silva Tiburcio, e-mail: xavier.andrea@ymail.com
}

TIBURCIO, A.S.X.S., KOENING, M.L., MACÊDO, S.J. \& MELO, P.A.M.C. Microphytoplankton community of São Pedro e São Paulo Archipelago (Atlantic North Equatorial): diurnal and spatial variation. Biota Neotrop. 11(2): http://www.biotaneotropica.org.br/v11n2/en/abstract?article+bn03811022011

\begin{abstract}
The present study was developed in the São Pedro and São Paulo Archipelago, with the objective to describe the structure of the microphytoplankton community, and establish its diurnal and spatial variation. The samplings were carried out in two stations (Enseada and Cabeço da Tartaruga) during five consecutive days (May 12 to 16, 2008) of the rainy season, during early morning and late afternoon, by subsurface horizontal hauls of 10 minutes duration with plankton net of $45 \mu \mathrm{m}$ of mesh size. A total of 131 taxa were recorded, out of which 117 in Cabeço station and 89 in Enseada. The group of dinoflagellates was the most diverse, represented by 90 taxa belonging to 17 genera, highlighting the Ceratium genus with 33 species. The cyanophyceae Trichodesmium thiebautti Gomon ex Gomont was the only dominant species in the area, influencing the community structure, and serving as indicator species for the area. There was a greater number of species at the Cabeço than in Enseada. The marine planktonic oceanic species predominated, with $61.26 \%$ of the overall species richness. The diversity and evenness were in general higher in both sampling stations. At Cabeço station, the values of species diversity were between a minimum of 0.76 bits.cell $^{-1}$ and a maximum of 4.27 bits.cell $^{-1}$ and evenness varied between 0.16 and 0.84 . At the Enseada station, it was registered a minimum of 2.91 bits.cell $^{-1}$ and a maximum of 3.87 bits.cell $^{-1}$, and evenness with minimum and maximum values of 0.64 and 0.84 , respectively. The cluster analysis showed the formation of three distinct associations of species, with Cabeço and Enseada species in separate groups, highlighting the differences between the communities of the two studied sites. In each station, there was no significant difference between samples of different hours. The study area is characterized by a floristic composition typical of stable, transparent and oligotrophic waters.
\end{abstract}

Keywords: brazilian northeastern waters, biodiversity, oceanic plankton, oceanic islands.

TIBURCIO, A.S.X.S., KOENING, M.L., MACÊDO, S.J. \& MELO, P.A.M.C. A Comunidade microfitoplanctônica do Arquipélago de São Pedro e São Paulo (Atlântico Norte - Equatorial): variação diurna e espacial. Biota Neotrop. 11(2): http://www.biotaneotropica.org.br/v11n2/pt/abstract?article+bn03811022011

Resumo: O presente trabalho foi desenvolvido no Arquipélago de São Pedro e São Paulo, com o objetivo de descrever a estrutura da comunidade microfitoplanctônica, assim como estabelecer sua variação diurna e espacial. As amostras foram coletadas em duas estações (Cabeço da Tartaruga e Enseada) durante cinco dias consecutivos (12 a 16/05/08) do período chuvoso, nos horários da manhã e da tarde, por meio de arrastos horizontais subsuperficiais de 10 minutos de duração, com uma rede de plâncton com abertura de malha de $45 \mu$ m. Um total de 131 táxons foram registrados, dos quais 117 foram na estação Cabeço da Tartaruga e 89 na Enseada. O grupo dos dinoflagelados foi o mais diverso, representado por 90 táxons pertencentes a 17 gêneros, destacando-se o gênero Ceratium com 33 espécies. A cianofícea Trichodesmium thiebautti Gomont ex Gomon foi a única espécie dominante na área, influenciando a estrutura da comunidade, servindo como a espécie indicadora da área. Houve um número maior de espécies na estação Cabeço do que na Enseada. As espécies marinhas planctônicas oceânicas predominaram, com $61,26 \%$ da riqueza total de espécies. A diversidade e a equitabilidade foram, no geral, altas em ambos locais de coleta. Na estação Cabeço, os valores de diversidade específica situaram-se entre

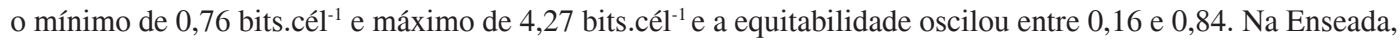
registraram-se mínimo de diversidade específica de 2,91 bits.cél ${ }^{-1}$ e máximo de 3,87 bits.cél $^{-1}$, e equitabilidade com valores mínimo e máximo de 0,64 e 0,84 , respectivamente. A análise de agrupamento mostrou a formação de três associações distintas de espécies, com espécies do Cabeço e da Enseada em grupos separados, evidenciando a diferença entre as comunidades dos dois locais estudados. Em cada estação, não houve diferença significativa entre as amostras dos diferentes horários. A área estudada está caracterizada por uma composição florística típica de ambiente estável, águas transparentes e oligotróficas.

Palavras-chave: águas do nordeste do brasil, biodiversidade, plâncton oceânico, ilhas oceânicas. 


\section{Introdução}

A região oceânica tropical do Atlântico é dominada pelas águas quentes e oligotróficas da Corrente Sul Equatorial, que se bifurca originando a Corrente Norte do Brasil e a Corrente do Brasil. O regime de ventos dominado pelos alíseos não favorece o desenvolvimento de ressurgências, ficando a Água Central do Atlântico Sul (ACAS) permanentemente abaixo da zona eufótica (Yoneda 1999).

Nesta região, bem como em outros ambientes marinhos, os organismos fitoplanctônicos sustentam a produtividade. $\mathrm{O}$ fitoplâncton é constituído por algas microscópicas, unicelulares, isoladas ou coloniais, que flutuam preferencialmente na superfície das águas (Gross \& Gross 1996) e a biodiversidade de dinoflagelados é comparável apenas com a das diatomáceas. Segundo Ricklefs (2003), alterações na composição e estrutura dessa comunidade podem ocasionar profundas mudanças em todos os níveis tróficos, uma vez que estes organismos apresentam um caráter muito dinâmico por possuírem elevadas taxas de reprodução, com ciclos de vida em torno de horas, dias ou semanas e respondem rapidamente às modificações das condições ambientais.

As comunidades fitoplanctônicas não têm sido tão extensivamente estudadas, talvez devido à facilidade com que se aceitou uma única medida (clorofila ou outros pigmentos) para representar a quantidade $\mathrm{e}$ o tipo de fitoplâncton presente. No entanto, sabe-se que as comunidades de fitoplâncton tropical são ricas em pequenas células; em oceanos tropicais abertos e oligotróficos, as diatomáceas são comparativamente menos importantes, enquanto os dinoflagelados, cocolitoforídeos e os pequenos flagelados nus dominam o plâncton vegetal eucariótico (Longhurst \& Pauly 2007). Entre os grupos fitoplanctônicos, os dinoflagelados se destacam por sua riqueza de espécies, diversidade morfológica e radiação adaptativa ao colonizar os diversos habitats encontrados nos oceanos. Dinoflagelados, como todas as microalgas pelágicas, devem ser capazes de sobreviver e crescer sob condições de distúrbio físico, estresse de luz intenso e limitação de nutrientes para alcançar um modo de vida planctônico (Smayda \& Reynolds 2002).

O Arquipélago de São Pedro e São Paulo (ASPSP), o menor arquipélago oceânico brasileiro, situa-se no meio do Atlântico-Norte Equatorial ( $00^{\circ} 55^{\prime} 02^{\prime \prime} \mathrm{N}$; $\left.29^{\circ} 20^{\prime} 42^{\prime \prime} \mathrm{O}\right)$, distando $1.010 \mathrm{~km}$ da costa brasileira e cerca de $1.824 \mathrm{~km}$ da costa africana (Campos et al. 2010). É formado por um grupo de pequenas ilhas rochosas desprovidas de qualquer tipo de vegetação. Com uma área de aproximadamente $17.000 \mathrm{~m}^{2}$, trata-se de região privilegiada para o desenvolvimento de pesquisas científicas. Segundo Omori \& Ikeda (1984), reúne características únicas, pelo que é possível compará-lo com um "oásis" em meio às águas do Oceano Atlântico.

Do ponto de vista científico, sua posição geográfica, entre os hemisférios Norte e Sul e os continentes africano e americano, atribui ao ASPSP uma condição única para a realização de pesquisas em diversos ramos da ciência, sendo uma área de enorme importância biológica, pois exerce papel relevante no ciclo de vida de várias espécies que têm no arquipélago etapa importante de suas rotas migratórias, quer como área de reprodução, quer como zona de alimentação (Porto 2006).

Informações sobre o microfitoplâncton em águas tropicais da plataforma externa e oceânica do Brasil são ainda muito escassas. Um dos primeiros trabalhos foi o de Müller-Melchers (1955), que publicou uma lista de diatomáceas com base em material do arquipélago de São Pedro e São Paulo. Em análise de amostras de plâncton coletadas nas proximidades do banco de Abrolhos pela Comissão Leste II do NOc. "Almirante Saldanha", os resultados mostraram que, apesar da maior diversidade em espécies de diatomáceas, os dinoflagelados dominaram quantitativamente, numa situação típica de águas oligotróficas (Macedo-Saidah \& Moreira-Filho 1977). Na mesma área, deve-se destacar o trabalho de Gaeta et al. (1999), que estudaram a biomassa e produtividade primária fitoplanctônica, tendo observado que o banco de Abrolhos mostrou-se oligotrófico, apresentando baixas concentrações de nutrientes, biomassa em termos de clorofila $a$ e baixas taxas de produtividade primária, enquanto que, na periferia do vórtice de Vitória, os resultados foram até duas vezes mais elevados. Complementando este estudo, Susini-Ribeiro (1999) avaliou a distribuição da biomassa do pico, nano e microfitoplâncton na plataforma continental de Abrolhos e constatou que o picoplâncton contribuiu com $64 \%$ da biomassa de carbono, o nanoplâncton $33 \%$ e o microfitoplâncton apenas $3 \%$. Apesar da comunidade do nano e microfitoplâncton contribuir com apenas $36 \%$ da biomassa total de carbono, é altamente diversificada.

No âmbito do Joint Oceanographic Project (JOPS II) foram também desenvolvidos estudos sobre produção e plâncton das águas da plataforma continental nordeste e leste do Brasil, incluindo o Arquipélago de São Pedro e São Paulo, Arquipélago de Fernando de Noronha, Bancos da Cadeia Norte Brasileira e Atol das Rocas. Nestes estudos, concluiu-se que o sistema pelágico do Nordeste e Leste do Brasil deve ser considerado como um sistema único, controlado principalmente pelo impacto de águas oligotróficas da Corrente Equatorial do Sul e correntes derivadas (Ekau \& Knoppers 1999). Bröckel \& Meyerhöfer (1999) estudaram, no Arquipélago de São Pedro e São Paulo, a composição da comunidade fitoplanctônica baseada na análise de pigmentos especiais através de cromatografia e espectrofotometria (clorofila $a$ e feopigmentos).

Koening \& Lira (2005), em estudo na plataforma continental e águas oceânicas do estado de Pernambuco, apresentaram as espécies e distribuição do gênero Ceratium, que se destacou na riqueza específica das amostras analisadas. Em estudo da biomassa fitoplanctônica na Zona Econômica Exclusiva do Nordeste, Mafalda Júnior et. al. (2009) constataram que os teores de clorofila- $a$ apresentaram um aumento na área adjacente ao Arquipélago de São Pedro e São Paulo. Koening \& Oliveira (2009), em estudo sobre a estrutura do fitoplâncton no Arquipélago de São Pedro e São Paulo, em oito estações posicionadas ao longo de dois transectos, constataram a presença de uma flora bem diversificada, composta em sua maioria de dinoflagelados.

O presente estudo tem como objetivo determinar a estrutura da comunidade microfitoplanctônica do Arquipélago de São Pedro e São Paulo, bem como estabelecer sua variação diurna e espacial.

\section{Material e Métodos}

As coletas foram realizadas por meio de arrastos horizontais subsuperficiais com duração de 10 minutos, a uma velocidade de dois a três nós, com o auxílio de rede de plâncton com abertura de malha de $45 \mu \mathrm{m}$ durante cinco dias consecutivos (12 a 16/05/08), no período chuvoso, com duas coletas diárias, pela manhã e à tarde, em duas estações fixas, uma localizada na estação Cabeço da Tartaruga $\left(00^{\circ} 55^{\prime}, 47^{\prime}, \mathrm{N} ; 2^{\circ} 37^{\prime}, 04^{\prime}\right.$ ' O $)$, uma área exposta e outra na estação Enseada ( $00^{\circ}$ 55', 08' ' N; 29²0', 73', O), área abrigada, no Arquipélago de São Pedro e São Paulo (Figura 1).

O material coletado foi fixado em formol neutro a $4 \%$. As amostras foram homogeneizadas e destas retiradas subamostras de $0,5 \mathrm{~mL}$ para a análise quali/quantitativa. A identificação e contagem dos táxons foram feitas em microscópio ótico, onde uma lâmina de Sedgwick-Rafter foi utilizada para quantificação e a análise qualitativa feita com uso de duas lâminas comuns, onde foram registrados os táxons não observados na lâmina de contagem.

A identificação e classificação dos táxons foram determinadas através de bibliografia especializada: Peragallo \& Peragallo (1897-1908), Hustedt (1930, 1959, 1961), Cupp (1943), Desikachary (1959), Taylor (1987), Balech (1988), Silva-Cunha \& Eskinazi-Leça (1990), Licea et al. (1995), Tomas (1997), Gómez (2005), Tenenbaum 
(2006). Os critérios de refinamento da identificação e os nomes científicos de espécies foram checados junto ao banco de dados internacional ALGAEBASE (http://www.algaebase.org/).

A abundância relativa dos táxons foi calculada segundo Lobo \& Leighton (1986), considerando as categorias: dominante ( $\geq 50 \%)$, abundante $(50 \% \mid-30 \%)$, pouco abundante $(30 \% \mid-10 \%)$ e rara $(\leq 10 \%)$. A diversidade específica de Shannon-Wiener $\left(\mathrm{H}^{\prime}=-\sum\right.$ pi.log $\log _{2}$ i) foi calculada, sendo considerada alta quando os resultados obtidos foram $\geq 3,0$ bits.cel $^{-1}$; média, com resultados entre 2 e 3 bits.cel $^{-1}$ baixa, entre 1 e 2 bits.cel $^{-1}$; e muito baixa, com resultado $\leq 1$ bit.cel $^{-1}$; e a equitabilidade $\left(\mathrm{J}=\mathrm{H}^{\prime} / \log \mathrm{S}\right)$, conforme Pielou (1977). Na frequência de ocorrência, os táxons foram considerados muito freqüentes ( $\geq 70 \%)$, freqüentes $(70 \%-40 \%)$, pouco frequientes $(40 \%-10 \%)$ ou esporádicos $(\leq 10 \%)$.

Os dados também foram analisados estatisticamente, sendo a similaridade entre as amostras avaliada com base no coeficiente de Bray-Curtis, utilizando-se os dados baseados na abundância relativa, transformados em raiz quarta, com método de amalgamento pela média do grupo, por meio do programa PRIMER 6 (Plymouth Routines In Multivariate Ecological Research). Através do teste de Mann-Whitney, utilizando o programa BioEstat 5.0 (Ayres et al. 2007), foi avaliada e comparada a comunidade fitoplanctônica entre os dois locais de estudo (Cabeço e Enseada) e o período de amostragem (manhã e tarde). A posteriori foi realizada a correção de Bonferroni. Esta consiste em determinar o valor do nível de significância individual (a), que proporcionará o nível de significância conjunto $\left(a^{*}=\mathrm{a} / \mathrm{c}\right)$ desejado, onde c é o número de possíveis combinações de médias. No presente estudo $\mathrm{a}=0,05$ e c $=2$. Desta forma o nível de significância $\mathrm{a}^{*}=0,025$.

\section{Resultados}

A comunidade microfitoplanctônica na área estudada esteve representada por 131 táxons. Houve diferença no número de táxons identificados nos locais de coleta, tendo sido 117 táxons na estação
Cabeço, com 42 táxons ocorrendo exclusivamente nesta estação e 89 na Enseada, esta com 13 táxons exclusivos (Tabela 1). O mesmo não ocorreu com o número de táxons nos períodos da manhã e tarde, que somaram 116 e 103 táxons, respectivamente, porém esta diferença não foi significativa. Analisando individualmente os horários em ambas as estações, observou-se que a estação Enseada apresentou o menor número de táxons nos dois horários, com 71 táxons ocorrendo pela manhã e 64 à tarde. A estação Cabeço apresentou 101 táxons pela manhã e 85 à tarde. De uma maneira geral, a maior variação no número de táxons foi registrada no período da tarde na estação Cabeço (Figura 2).

Foi registrada apenas uma espécie dominante, a cianobactéria Trichodesmium thiebautii Gomont ex Gomont (Figura 3). À exceção dos dinoflagelados Ceratium pentagonum var. tenerum Jörgensen e Goniodoma polyedricum (Pouchet) Jörgensen, e das diatomáceas Climacosphenia elongata Bailey, Climacosphenia moniligera (Lyng.) Kützing, Hemiaulus membranaceus Cleve e Leptocylindrus danicus Cleve, considerados pouco abundantes e Licmophora ehrenbergii (Kützing) Grunow, classificada como abundante, todos os outros táxons foram considerados raros, com percentuais inferiores a $10 \%$.

Dos 131 táxons identificados, $46 \%$ foram esporádicos, $28 \%$ foram pouco frequentes, $15 \%$ foram considerados frequentes e $11 \%$ foram muito frequentes. Dentre os 15 táxons muito frequentes registrados, estão Oscillatoria sp., Trichodesmium thiebautii, Ceratium declinatum var. declinatum (Karsten) Jörgensen, Ceratium pentagonum var. tenerum, Ceratium teres Kofoid, Goniodoma polyedricum, Phalacroma argus Stein, Phalacroma doryphorum Stein, Protoperidinium latispinum Mangin, Pyrocystis noctiluca Murray ex Haeckel, Climacosphenia elongata, Climacosphenia moniligera, Hemiaulus membranaceus, Leptocylindrus danicus e Rhabdonema adriaticum Kützing.

A comunidade microfitoplanctônica apresentou altos índices de diversidade específica, assim como a equitabilidade. No geral, $65 \%$ das amostras apresentaram uma alta diversidade e $70 \%$ alta

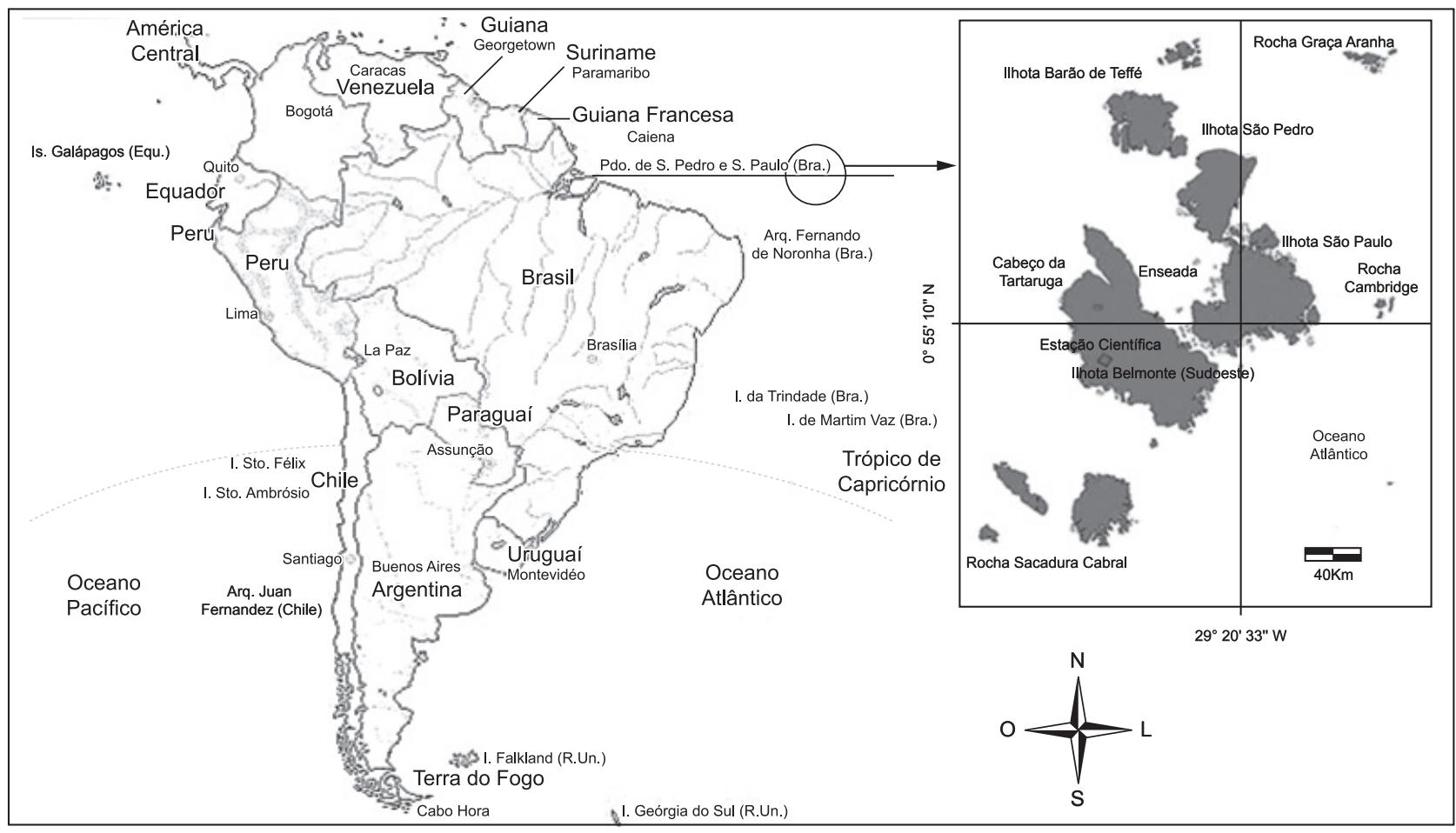

Figura 1. Estações de coleta no Arquipélago de São Pedro e São Paulo (estações Cabeço da Tartaruga e Enseada).

Figure 1. Collection stations at São Pedro e São Paulo Archipelago (Cabeço da Tartaruga and Enseada stations). 
Tabela 1. Lista dos táxons identificados nas estações Cabeço da Tartaruga e Enseada, no Arquipélago de São Pedro e São Paulo.

Table 1. List of taxa identified in the stations Cabeço da Tartaruga and Enseada, at São Pedro e São Paulo Archipelago.

\begin{tabular}{|c|c|c|c|c|}
\hline \multirow[t]{3}{*}{ Táxons } & \multicolumn{4}{|c|}{ Estações } \\
\hline & \multicolumn{2}{|c|}{ Cabeço } & \multicolumn{2}{|c|}{ Enseada } \\
\hline & Manhã & Tarde & Manhã & Tarde \\
\hline \multicolumn{5}{|l|}{ CYANOBACTERIA } \\
\hline \multicolumn{5}{|l|}{ CYANOPHYCEAE } \\
\hline \multicolumn{5}{|l|}{ OSCILLATORIALES } \\
\hline \multicolumn{5}{|l|}{ OSCILLATORIACEAE } \\
\hline Oscillatoria sp. & $\mathrm{X}$ & $\mathrm{X}$ & $\mathrm{X}$ & $\mathrm{X}$ \\
\hline \multicolumn{5}{|l|}{ PHORMIDICAEA } \\
\hline Trichodesmium thiebautii Gomont ex Gomont & $\mathrm{X}$ & $\mathrm{X}$ & $\mathrm{X}$ & $\mathrm{X}$ \\
\hline \multicolumn{5}{|l|}{ DINOFLAGELLATA } \\
\hline \multicolumn{5}{|l|}{ PROROCENTRALES } \\
\hline \multicolumn{5}{|l|}{ PROROCENTRACEAE } \\
\hline Prorocentrum balticum (Lohmann) Loeblich III & $\mathrm{X}$ & $\mathrm{X}$ & $\mathrm{X}$ & $\mathrm{X}$ \\
\hline Prorocentrum compressum (Bailey) Abé ex Dodge & - & $\mathrm{X}$ & - & - \\
\hline Prorocentrum gracile Schütt & - & - & $\mathrm{X}$ & $\mathrm{X}$ \\
\hline Prorocentrum micans Ehrenberg & - & - & $\mathrm{X}$ & - \\
\hline Prorocentrum sigmoides Ehrenberg & $X$ & $\mathrm{X}$ & - & - \\
\hline Prorocentrum sp. & - & $\mathrm{X}$ & $\mathrm{X}$ & - \\
\hline \multicolumn{5}{|l|}{ DINOPHYSIALES } \\
\hline \multicolumn{5}{|l|}{ DINOPHYSIACEAE } \\
\hline *Dinophysis hastata Stein & $\mathrm{X}$ & $\mathrm{X}$ & $X$ & - \\
\hline *Dinophysis schuettii Murray \& Whitting & $\mathrm{X}$ & - & - & - \\
\hline Dinophysis sp. & $\mathrm{X}$ & - & - & - \\
\hline *Histioneis crateriformis Stein & - & - & - & $\mathrm{X}$ \\
\hline Histioneis hippoperoides Stein & $\mathrm{X}$ & - & - & - \\
\hline Ornithocercus magnificus Stein & $\mathrm{X}$ & $\mathrm{X}$ & $\mathrm{X}$ & $\mathrm{X}$ \\
\hline Ornithocercus quadratus Schütt & - & $\mathrm{X}$ & $\mathrm{X}$ & $\mathrm{X}$ \\
\hline Ornithocercus steinii Schütt & $\mathrm{X}$ & - & $\mathrm{X}$ & $\mathrm{X}$ \\
\hline Ornithocercus thumii (Schmidt) Kofoid \& Skogsberg & $\mathrm{X}$ & - & - & $\mathrm{X}$ \\
\hline Phalacroma argus Stein & $\mathrm{X}$ & $\mathrm{X}$ & $\mathrm{X}$ & $\mathrm{X}$ \\
\hline Phalacroma cuneus Schütt & $\mathrm{X}$ & $\mathrm{X}$ & $\mathrm{X}$ & - \\
\hline *Phalacroma doryphorum Stein & $\mathrm{X}$ & $\mathrm{X}$ & - & $\mathrm{X}$ \\
\hline Phalacroma rapa Jorgensen & $\mathrm{X}$ & $\mathrm{X}$ & $\mathrm{X}$ & - \\
\hline Phalacroma rotundatum (Claparèd \& Lechmann) Kofoid \& Michener & $\mathrm{X}$ & $\mathrm{X}$ & $\mathrm{X}$ & $\mathrm{X}$ \\
\hline \multicolumn{5}{|l|}{ GONYAULACALES } \\
\hline \multicolumn{5}{|l|}{ CERATIACEAE } \\
\hline Ceratium arietinum Cleve & - & $\mathrm{X}$ & $\mathrm{X}$ & - \\
\hline Ceratium candelabrum Ehrenberg & $\mathrm{X}$ & $\mathrm{X}$ & $\mathrm{X}$ & $\mathrm{X}$ \\
\hline Ceratium contortum var. contortum (Gourret) Cleve & - & - & $\mathrm{X}$ & $\mathrm{X}$ \\
\hline *Ceratium declinatum var. angusticornum (Karsten) Jörgensen & $\mathrm{X}$ & $\mathrm{X}$ & $\mathrm{X}$ & $\mathrm{X}$ \\
\hline Ceratium declinatum var. declinatum (Karsten) Jörgensen & $\mathrm{X}$ & $\mathrm{X}$ & $\mathrm{X}$ & $\mathrm{X}$ \\
\hline Ceratium extensum (Gourret) Cleve & $\mathrm{X}$ & $\mathrm{X}$ & - & $\mathrm{X}$ \\
\hline Ceratium fusus (Ehrenberg) Dujardin & $\mathrm{X}$ & $\mathrm{X}$ & - & $\mathrm{X}$ \\
\hline Ceratium fusus (Ehrenberg) Dujardin var. fusus & $\mathrm{X}$ & $\mathrm{X}$ & - & - \\
\hline Ceratium fusus var. seta (Ehrenberg) Sournia & $\mathrm{X}$ & $\mathrm{X}$ & $\mathrm{X}$ & $\mathrm{X}$ \\
\hline Ceratium geniculatum (Lemmermman) Cleve & - & $\mathrm{X}$ & $\mathrm{X}$ & - \\
\hline Ceratium gibberum Gourret & $\mathrm{X}$ & - & $\mathrm{X}$ & - \\
\hline
\end{tabular}

*Novas ocorrências. 
Tabela 1. Continuação...

\begin{tabular}{|c|c|c|c|c|}
\hline \multirow[t]{3}{*}{ Táxons } & \multicolumn{4}{|c|}{ Estações } \\
\hline & \multicolumn{2}{|c|}{ Cabeço } & \multicolumn{2}{|c|}{ Enseada } \\
\hline & Manhã & Tarde & Manhã & Tarde \\
\hline Ceratium hexacanthum Gourret & - & - & - & $\mathrm{X}$ \\
\hline Ceratium horridum (Cleve) Gran & $\mathrm{X}$ & $\mathrm{X}$ & $\mathrm{X}$ & $\mathrm{X}$ \\
\hline *Ceratium horridum var. molle (Kofoid) Jörgensen & - & $\mathrm{X}$ & - & - \\
\hline Ceratium incisum (Karsten) Jörgensen & $\mathrm{X}$ & - & $\mathrm{X}$ & $\mathrm{X}$ \\
\hline Ceratium lineatum (Ehrenberg) Cleve & - & - & $\mathrm{X}$ & $\mathrm{X}$ \\
\hline Ceratium longirostrum Gourret & - & $\mathrm{X}$ & $\mathrm{X}$ & - \\
\hline Ceratium lunula (Schimper) Jörgensen & $\mathrm{X}$ & - & - & - \\
\hline Ceratium macroceros var. macroceros (Ehrenberg) Vänhoffen & $\mathrm{X}$ & $\mathrm{X}$ & $\mathrm{X}$ & - \\
\hline Ceratium massiliense var. massiliense Sournia & - & $\mathrm{X}$ & - & - \\
\hline Ceratium massiliense var. armatum (Karsten) Jörgensen & $\mathrm{X}$ & $\mathrm{X}$ & - & $\mathrm{X}$ \\
\hline Ceratium paradoxides Cleve & $\mathrm{X}$ & - & - & - \\
\hline Ceratium pentagonum var. longisetum (Ostenfeld \& Schmidt) Jörgensen & $\mathrm{X}$ & $\mathrm{X}$ & $\mathrm{X}$ & $\mathrm{X}$ \\
\hline Ceratium pentagonum var. tenerum Jörgensen & $\mathrm{X}$ & $\mathrm{X}$ & $\mathrm{X}$ & $\mathrm{X}$ \\
\hline Ceratium reflexum Cleve & $\mathrm{X}$ & $\mathrm{X}$ & - & - \\
\hline *Ceratium strictum (Kofoid) E.G.Jørgensen & $\mathrm{X}$ & - & - & $\mathrm{X}$ \\
\hline Ceratium symmetricum var. symmetricum Graham \& Bronikowsky & $\mathrm{X}$ & $\mathrm{X}$ & - & - \\
\hline Ceratium teres Kofoid & $\mathrm{X}$ & $\mathrm{X}$ & $\mathrm{X}$ & $\mathrm{X}$ \\
\hline Ceratium tripos (O. F. Müller) Nitzsch & - & $\mathrm{X}$ & - & - \\
\hline Ceratium tripos var. pulchellum (Schröder) López & $\mathrm{X}$ & - & - & $\mathrm{X}$ \\
\hline Ceratium tripos var. tripos (O. F. Müller) Nitzsch & $\mathrm{X}$ & - & - & - \\
\hline Ceratium vultur var. vultur Cleve & $\mathrm{X}$ & $\mathrm{X}$ & $\mathrm{X}$ & $\mathrm{X}$ \\
\hline Ceratium sp. & - & - & $\mathrm{X}$ & - \\
\hline \multicolumn{5}{|l|}{ CERATOCORYTHACEAE } \\
\hline Ceratocorys horrida Stein & $\mathrm{X}$ & $\mathrm{X}$ & $\mathrm{X}$ & - \\
\hline Ceratocorys sp. & $\mathrm{X}$ & - & - & - \\
\hline \multicolumn{5}{|l|}{ GONIODOMATACEAE } \\
\hline Goniodoma polyedricum (Pouchet) Jörgensen & $\mathrm{X}$ & $\mathrm{X}$ & $\mathrm{X}$ & $\mathrm{X}$ \\
\hline \multicolumn{5}{|l|}{ GONYAULACACEAE } \\
\hline *Gonyaulax birostris Stein & $\mathrm{X}$ & - & - & - \\
\hline Gonyaulax pacifica Kofoid & $\mathrm{X}$ & $\mathrm{X}$ & $\mathrm{X}$ & $\mathrm{X}$ \\
\hline Gonyaulax polygramma Stein & $\mathrm{X}$ & $\mathrm{X}$ & $\mathrm{X}$ & $\mathrm{X}$ \\
\hline Gonyalax spinifera (Clap. \& Lach.) Diesing & $\mathrm{X}$ & $\mathrm{X}$ & - & - \\
\hline Gonyaulax sp. & $\mathrm{X}$ & $\mathrm{X}$ & $\mathrm{X}$ & $\mathrm{X}$ \\
\hline Gonyaulax sp1 & $\mathrm{X}$ & $\mathrm{X}$ & $\mathrm{X}$ & - \\
\hline Lingulodinium polyedrum (Stein) Dodge & $\mathrm{X}$ & $\mathrm{X}$ & $X$ & - \\
\hline Spiniferites sp. & - & - & - & $X$ \\
\hline \multicolumn{5}{|l|}{ OXYTOXACEAE } \\
\hline Corythodinium belgicae Meunier & - & $\mathrm{X}$ & - & - \\
\hline Corythodinium constrictum (Stein) F.J.R. Taylor & - & $\mathrm{X}$ & $\mathrm{X}$ & - \\
\hline *Corythodinium elegans (Pavillard) F.J.R. Taylor & $\mathrm{X}$ & $\mathrm{X}$ & $\mathrm{X}$ & - \\
\hline *Corythodinium tesselatum (Stein) Loeblich Jr. \& Loeblich III & $\mathrm{X}$ & - & $\mathrm{X}$ & - \\
\hline Corythodinium sp. & $\mathrm{X}$ & $\mathrm{X}$ & - & - \\
\hline *Oxytoxum crassum Schiller & $\mathrm{X}$ & $\mathrm{X}$ & - & $\mathrm{X}$ \\
\hline *Oxytoxum milneri Murray \& Whitting & - & $\mathrm{X}$ & - & - \\
\hline Oxytoxum scolopax Stein & $\mathrm{X}$ & - & - & $\mathrm{X}$ \\
\hline Oxytoxum sp. & $\mathrm{X}$ & $\mathrm{X}$ & - & - \\
\hline PYROCYSTALES & & & & \\
\hline
\end{tabular}

*Novas ocorrências. 


\begin{tabular}{|c|c|c|c|c|}
\hline \multirow[t]{3}{*}{ Táxons } & \multicolumn{4}{|c|}{ Estações } \\
\hline & \multicolumn{2}{|c|}{ Cabeço } & \multicolumn{2}{|c|}{ Enseada } \\
\hline & Manhã & Tarde & Manhã & Tarde \\
\hline \multicolumn{5}{|l|}{ PYROCYSTACEAE } \\
\hline Pyrocystis fusiformis (W. Thomson) Murray & $\mathrm{X}$ & - & - & - \\
\hline Pyrocystis lunula (Schütt) Schütt & $\mathrm{X}$ & - & - & $\mathrm{X}$ \\
\hline Pyrocystis noctiluca Murray ex Haeckel & $\mathrm{X}$ & $\mathrm{X}$ & $\mathrm{x}$ & $\mathrm{X}$ \\
\hline Pyrocystis robusta Kofoid & $\mathrm{X}$ & $\mathrm{X}$ & $\mathrm{X}$ & $\mathrm{X}$ \\
\hline \multicolumn{5}{|l|}{ PYROPHACACEAE } \\
\hline Pyrophacus horologium Stein & $\mathrm{X}$ & - & - & $\mathrm{X}$ \\
\hline Pyrophacus steinii (Schiller) Wall \& Dale & $\mathrm{X}$ & $\mathrm{x}$ & - & - \\
\hline \multicolumn{5}{|l|}{ PERIDINIACEAE } \\
\hline Podolampas bipes Stein & $\mathrm{X}$ & $\mathrm{X}$ & - & - \\
\hline Podolampas elegans Schütt & $\mathrm{X}$ & - & $\mathrm{X}$ & - \\
\hline Podolampas palmipes Stein & $\mathrm{X}$ & $\mathrm{X}$ & $\mathrm{X}$ & $\mathrm{X}$ \\
\hline Podolampas spinifera Okamura & $\mathrm{X}$ & $\mathrm{X}$ & - & - \\
\hline \multicolumn{5}{|l|}{ PROTOPERIDINIACEAE } \\
\hline *Protoperidinium cerasus (Paulsen) Balech & $\mathrm{X}$ & $\mathrm{X}$ & $\mathrm{X}$ & - \\
\hline *Protoperidinium depressum (Bailey) Balech & $\mathrm{X}$ & $\mathrm{X}$ & $\mathrm{X}$ & $\mathrm{X}$ \\
\hline *Protoperidinium divergens (Ehrenberg) Balech & - & $\mathrm{X}$ & $\mathrm{X}$ & - \\
\hline Protoperidinium latispinum Mangin & $\mathrm{X}$ & $\mathrm{X}$ & $\mathrm{X}$ & $\mathrm{X}$ \\
\hline *Protoperidinium obtusum (Karsten) Parke \& Dodge & - & $\mathrm{X}$ & - & - \\
\hline *Protoperidinium subpyriforme Dangeard & $\mathrm{X}$ & $\mathrm{X}$ & - & $\mathrm{X}$ \\
\hline Protoperidinium sp. & $\mathrm{x}$ & $\mathrm{X}$ & $\mathrm{X}$ & $\mathrm{X}$ \\
\hline \multicolumn{5}{|l|}{ BACILLARIOPHYTA } \\
\hline \multicolumn{5}{|l|}{ COSCINODISCOPHYCEAE } \\
\hline \multicolumn{5}{|l|}{ COSCINODISCALES } \\
\hline \multicolumn{5}{|l|}{ COSCINODISCACEAE } \\
\hline Coscinodiscus centralis Ehrenberg & $\mathrm{X}$ & - & - & - \\
\hline Concinodiscus oculusiridis Ehrenberg & $\mathrm{X}$ & $\mathrm{X}$ & - & - \\
\hline Coscinodiscus sp. & $\mathrm{X}$ & - & - & - \\
\hline \multicolumn{5}{|l|}{ RHIZOSOLENIALES } \\
\hline \multicolumn{5}{|l|}{ RHIZOSOLENIACEAE } \\
\hline Rhizosolenia styliformis Brightwell & $\mathrm{X}$ & $\mathrm{X}$ & $\mathrm{X}$ & $\mathrm{X}$ \\
\hline \multicolumn{5}{|l|}{ HELIOPELTACEAE } \\
\hline Actinoptychus sp. & $\mathrm{X}$ & - & $\mathrm{X}$ & - \\
\hline \multicolumn{5}{|l|}{ MEDIOPHYCEAE } \\
\hline \multicolumn{5}{|l|}{ TRICERATIALES } \\
\hline Triceratium alternans Bailey & - & - & - & $\mathrm{X}$ \\
\hline Triceratium antidiluvianum Grunow & $\mathrm{X}$ & $\mathrm{X}$ & $\mathrm{X}$ & $\mathrm{X}$ \\
\hline Triceratium elongatum Grunow & - & - & $\mathrm{X}$ & - \\
\hline Triceratium orbiculatum Shadbolt & - & - & $\mathrm{X}$ & - \\
\hline Triceratium shadboltianum Greville & - & - & $\mathrm{x}$ & $\mathrm{X}$ \\
\hline Pleurosira laevis (Ehrenberg) Campère & $\mathrm{X}$ & $\mathrm{X}$ & $\mathrm{X}$ & $\mathrm{X}$ \\
\hline \multicolumn{5}{|l|}{ BIDDULPHIALES } \\
\hline \multicolumn{5}{|l|}{ BIDDULPHIACEAE } \\
\hline Biddulphia biddulphiana Smith & $\mathrm{X}$ & $\mathrm{X}$ & $\mathrm{X}$ & $\mathrm{X}$ \\
\hline \multicolumn{5}{|l|}{ HEMIAULALES } \\
\hline HEMIAULACEAE & & & & \\
\hline
\end{tabular}

*Novas ocorrências. 
Tabela 1. Continuação...

\begin{tabular}{|c|c|c|c|c|}
\hline \multirow[t]{3}{*}{ Táxons } & \multicolumn{4}{|c|}{ Estações } \\
\hline & \multicolumn{2}{|c|}{ Cabeço } & \multicolumn{2}{|c|}{ Enseada } \\
\hline & Manhã & Tarde & Manhã & Tarde \\
\hline Hemiaulus membranaceus Cleve & $\mathrm{X}$ & $X$ & $\mathrm{X}$ & $\mathrm{X}$ \\
\hline \multicolumn{5}{|l|}{ CHAETOCEROTALES } \\
\hline \multicolumn{5}{|l|}{ CHAETOCEROTACEAE } \\
\hline Chaetoceros atlanticus Cleve & $\mathrm{X}$ & - & - & - \\
\hline Chaetoceros coarctatus Lauder & $\mathrm{X}$ & $\mathrm{X}$ & - & - \\
\hline Chaetoceros lorenzianus Grunow & $\mathrm{X}$ & $\mathrm{X}$ & - & - \\
\hline Chaetocerus peruvianus Brightwell & $\mathrm{X}$ & - & - & - \\
\hline Chaetoceros sp. & $\mathrm{X}$ & $\mathrm{X}$ & - & - \\
\hline \multicolumn{5}{|l|}{ LEPTOCYLINDRALES } \\
\hline \multicolumn{5}{|l|}{ LEPTOCYLINDRACEAE } \\
\hline Leptocylindrus danicus Cleve & $\mathrm{X}$ & $X$ & $\mathrm{X}$ & $\mathrm{X}$ \\
\hline \multicolumn{5}{|l|}{ BACILLARIOPHYCEAAE } \\
\hline \multicolumn{5}{|l|}{ FRAGILARIALES } \\
\hline \multicolumn{5}{|l|}{ FRAGILARIACEAE } \\
\hline Synedra undulata (J.W. Bailey) Gregory & $\mathrm{X}$ & - & - & - \\
\hline Synedra sp. & $\mathrm{X}$ & $\mathrm{X}$ & $\mathrm{X}$ & - \\
\hline Podocystis americana Kützing & $\mathrm{X}$ & - & - & - \\
\hline \multicolumn{5}{|l|}{ LICMOPHORALES } \\
\hline \multicolumn{5}{|l|}{ LICMOPHORACEAE } \\
\hline Licmophora abbreviata Agardh & $\mathrm{X}$ & $\mathrm{X}$ & $\mathrm{X}$ & $\mathrm{X}$ \\
\hline Licmophora ehrenbergii (Kützing) Grunow & & $\mathrm{X}$ & $\mathrm{X}$ & $\mathrm{X}$ \\
\hline Licmophora ehrenbergii var. ovata Smith & & $\mathrm{X}$ & & \\
\hline Licmophora gracilis Agardh & $\mathrm{X}$ & - & - & - \\
\hline Licmophora sp. & $\mathrm{X}$ & $\mathrm{X}$ & $X$ & $\mathrm{X}$ \\
\hline \multicolumn{5}{|l|}{ RHABDONEMATALES } \\
\hline \multicolumn{5}{|l|}{ RHABDONEMATACEAE } \\
\hline Rhabdonema adriatricum Kutzing & $\mathrm{X}$ & $X$ & $\mathrm{X}$ & $\mathrm{X}$ \\
\hline Rhabdonema punctatum (Harvey \& Barley) Stodder & - & - & $X$ & $\mathrm{X}$ \\
\hline \multicolumn{5}{|l|}{ STRIATELLALES } \\
\hline \multicolumn{5}{|l|}{ STRIATELLACEAE } \\
\hline Grammatophora sp. & $\mathrm{X}$ & - & - & - \\
\hline \multicolumn{5}{|l|}{ CLIMACOSPHENIALES } \\
\hline \multicolumn{5}{|l|}{ CLIMACOSPHENIACEAE } \\
\hline Climacosphenia elongata Bailey & $\mathrm{X}$ & $\mathrm{X}$ & $\mathrm{X}$ & $\mathrm{X}$ \\
\hline Climacosphenia moniligera (Lyng.) Kützing & $\mathrm{X}$ & $\mathrm{X}$ & $\mathrm{X}$ & $\mathrm{X}$ \\
\hline \multicolumn{5}{|l|}{ NAVICULALES } \\
\hline \multicolumn{5}{|l|}{ NAVICULACEAE } \\
\hline Navicula sp. & $\mathrm{X}$ & $\mathrm{X}$ & - & - \\
\hline Navicula sp1. & $\mathrm{X}$ & $\mathrm{X}$ & $X$ & $X$ \\
\hline THALASSIOPHYSALES & & & & \\
\hline CATENULACEAE & & & & \\
\hline Amphora sp. & $\mathrm{X}$ & - & - & - \\
\hline BACILLARIALES & & & & \\
\hline BACILLARIACEAE & & & & \\
\hline Cylindrotheca closterium (Ehrenberg) Reimann \& J.C.Lewin & $\mathrm{X}$ & - & $\mathrm{X}$ & $\mathrm{X}$ \\
\hline Nitzschia longissima (Brébisson) Ralfs & $\mathrm{X}$ & - & - & - \\
\hline Nitzschia sp. & - & $\mathrm{X}$ & - & $\mathrm{X}$ \\
\hline Pseudo-nitzschia sp. & $\mathrm{X}$ & - & - & - \\
\hline
\end{tabular}

*Novas ocorrências. 
equitabilidade, demonstrando que a comunidade tem boa repartição da abundância.

$\mathrm{Na}$ estação Cabeço, os valores de diversidade específica situaram-se entre o mínimo de 0,76 bits.cél $^{-1}$ e máximo de 4,27 bits.cél $^{-1}$, com $50 \%$ das amostras apresentando alta diversidade, enquanto a equitabilidade oscilou entre 0,16 e 0,84 , com $40 \%$ das amostras apresentando alta equitabilidade. Na Enseada, registraram-se

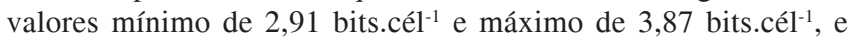
equitabilidade, com valores mínimo e máximo de 0,64 e 0,84 , respectivamente, sendo que $80 \%$ das amostras apresentaram alta diversidade e $100 \%$ delas alta equitabilidade (Figura 4).

No local, as espécies marinhas planctônicas oceânicas tiveram destaque, com percentual de $61,82 \%$, seguidas pelas ticoplanctônicas, com percentual de 14,54\%, marinhas planctônicas neríticas, com 10\% e marinhas planctônicas neríticas/oceânicas, com 13,64\%.

Através da análise de agrupamento foi observada a formação de três grandes grupos (A, B e C; Figura 5). O grupo A foi subdividido em dois subgrupos (A1 e A2), onde A1 foi formado pelas amostras da manhã e da tarde coletadas no primeiro dia (12/05/08) na Enseada, marcadas por uma maior quantidade das espécies de diatomáceas Climacosphenia elongata, Climacosphenia moniligera, Leptocylindrus danicus e Licmophora ehrenbergii, além da cianofícea Trichodesmium thiebautii. O subgrupo A2 esteve representado por quatro amostras da estação Cabeço, onde ocorreu a dominância de Trichodesmium thiebautii, sendo estas da manhã e da tarde do primeiro dia, a amostra da manhã do segundo dia (13/05/08) e a da tarde do terceiro dia (14/05/08). O grupo B foi formado pelo restante das amostras da Enseada (todas as amostras de ambos os horários do segundo, terceiro, quarto e quinto dias), onde não houve destaque de nenhuma espécie em particular, mas do grupo das diatomáceas, que se destacaram na abundância. $\mathrm{O}$ grupo $\mathrm{C}$ foi formado pelo restante das amostras da estação Cabeço, onde não houve destaque de nenhuma espécie.

De acordo com o teste de Mann-Whitney, entre as amostras coletadas nos diferentes horários não houve diferença significativa. No entanto, ocorreram diferenças ao se comparar as amostras coletadas nas duas estações de coleta, entre as amostras do segundo dia à tarde (Mann-Whitney, $\mathrm{p}=0,0258)$ e as do quarto dia, também à tarde (Mann-Whitney, $\mathrm{p}=0,0244)$. Como o nível de significância bonferronizado é 0,025 , as diferenças significativas ocorreram apenas entre as amostras do quarto dia, coletadas à tarde.

\section{Discussão}

As águas oceânicas do Nordeste do Brasil são caracterizadas por baixa produtividade primária, devido à existência de uma termoclina permanente na região, a qual não permite que águas profundas ricas em nutrientes se misturem com águas superficiais. Este não favorecimento de ressurgências mantém a camada superior da coluna da água oligotrófica, favorecendo assim as espécies fitoplânctônicas adaptadas a este tipo de ambiente (Travassos et al. 1999). Nestas áreas, o fitoplâncton, principal produtor primário dos ecossistemas marinhos, depende basicamente de dois fatores: luz e nutrientes (Lalli \& Parsons 1997).

O número total de espécies encontradas na área estudada pode ser considerado elevado para águas oligotróficas relativamente distantes da costa e aparentemente livre de influências continentais, entretanto é comparável com estudos realizados na plataforma continental do

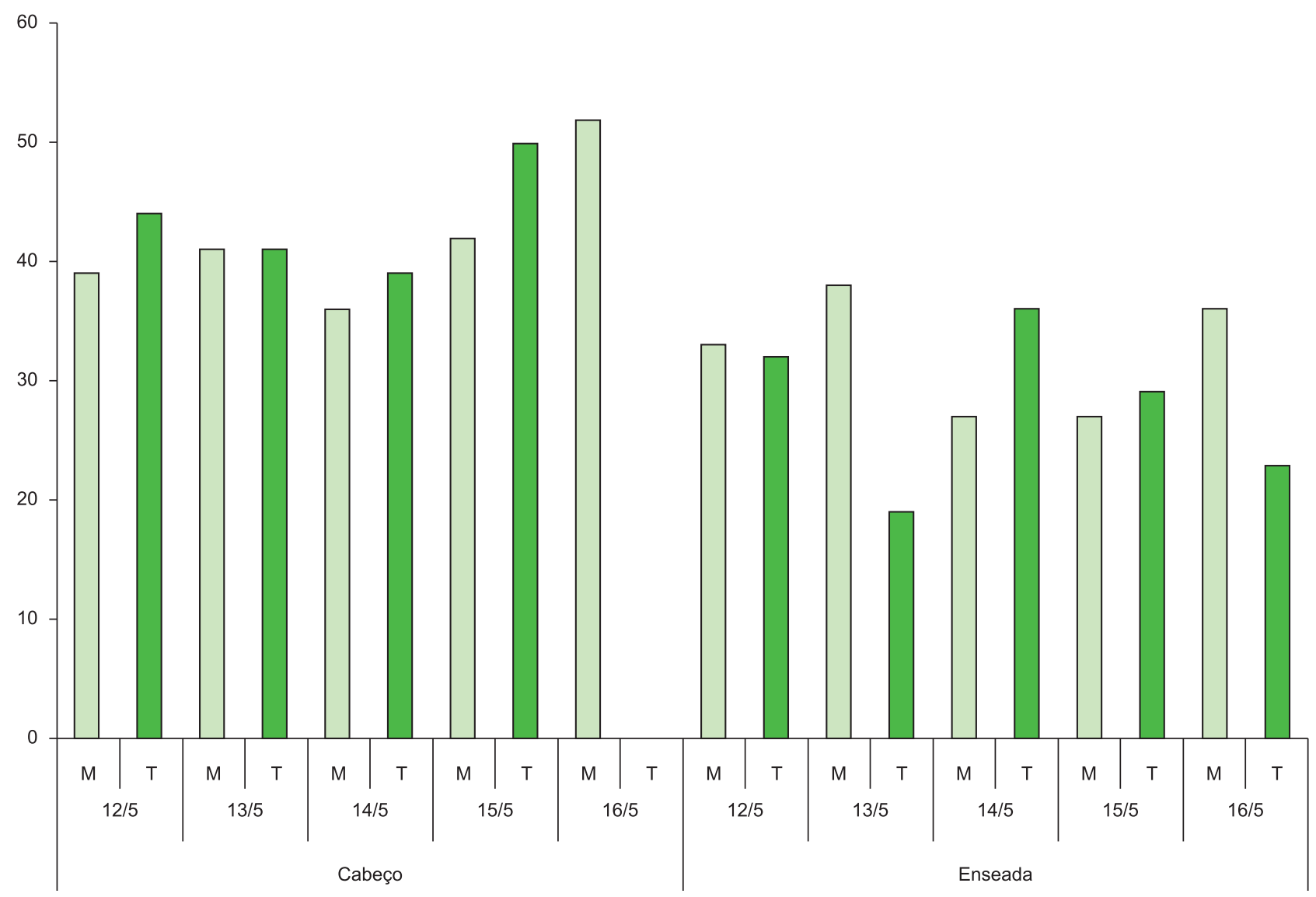

Figura 2. Riqueza de espécies nos locais e períodos estudados. $\mathrm{M}=$ manhã e $\mathrm{T}=\operatorname{tarde}$.

Figure 2. Species richness in sites and periods studied. $\mathrm{M}=$ morning and $\mathrm{T}=$ afternoon. 
Nordeste do Brasil (Eskinazi-Leça \& Passavante 1972, Passavante 1979, Koening \& Macêdo (1999), Medeiros et al. (1999), Galvão 2000, Eskinazi-Leça et.al. 2002, Koening \& Lira 2005, Koening et al. 2009).

Dos 131 táxons registrados para a área estudada, 17 representam novas ocorrências para o Nordeste do Brasil e 90 táxons pertencem aos dinoflagelados, em sua maioria representados por espécies do gênero Ceratium, que forma um componente muito importante do fitoplâncton marinho. Este gênero está presente em todos os oceanos do mundo, tendo assim um extraordinário alcance biogeográfico, desde as águas quentes dos trópicos até as frias águas polares. Ceratium também forma um componente principal do plâncton em termos de sua biomassa e, por causa da sua fototrofia, na produtividade primária (Dodge \& Marshall 1994). No Arquipélago de São Pedro e São Paulo foram registradas 19 espécies e 14 variedades deste gênero, num total de 33 táxons, dentre os quais três são tidos como novas ocorrências na região Nordeste: Ceratium declinatum var. angusticornum (Karsten) Jörgensen, Ceratium horridum var. molle (Kofoid) Jörgensen e Ceratium strictum (Kofoid) E.G.Jörgensen.

Trabalhos sobre fitoplâncton em áreas de plataforma continental na região tropical também destacaram a riqueza específica do gênero Ceratium (Passavante 1979, Koening \& Macêdo 1999, Medeiros et al. 1999, Eskinazi-Leça et al. 2002, Koening \& Lira 2005).

Koening \& Oliveira (2009), em coletas ao longo dos transectos no entorno do Arquipélago de São Pedro e São Paulo, identificaram 47 táxons, corroborando a riqueza do gênero Ceratium. Para a região Sueste do Brasil, Brandini \& Moraes (1986) identificaram 87 táxons, com destaque para as diatomáceas e dinoflagelados, com 49 e 33 táxons, respectivamente e Tenenbaum et al. (2007), para a região central da Zona Econômica Exclusiva brasileira, identificaram 51 táxons.

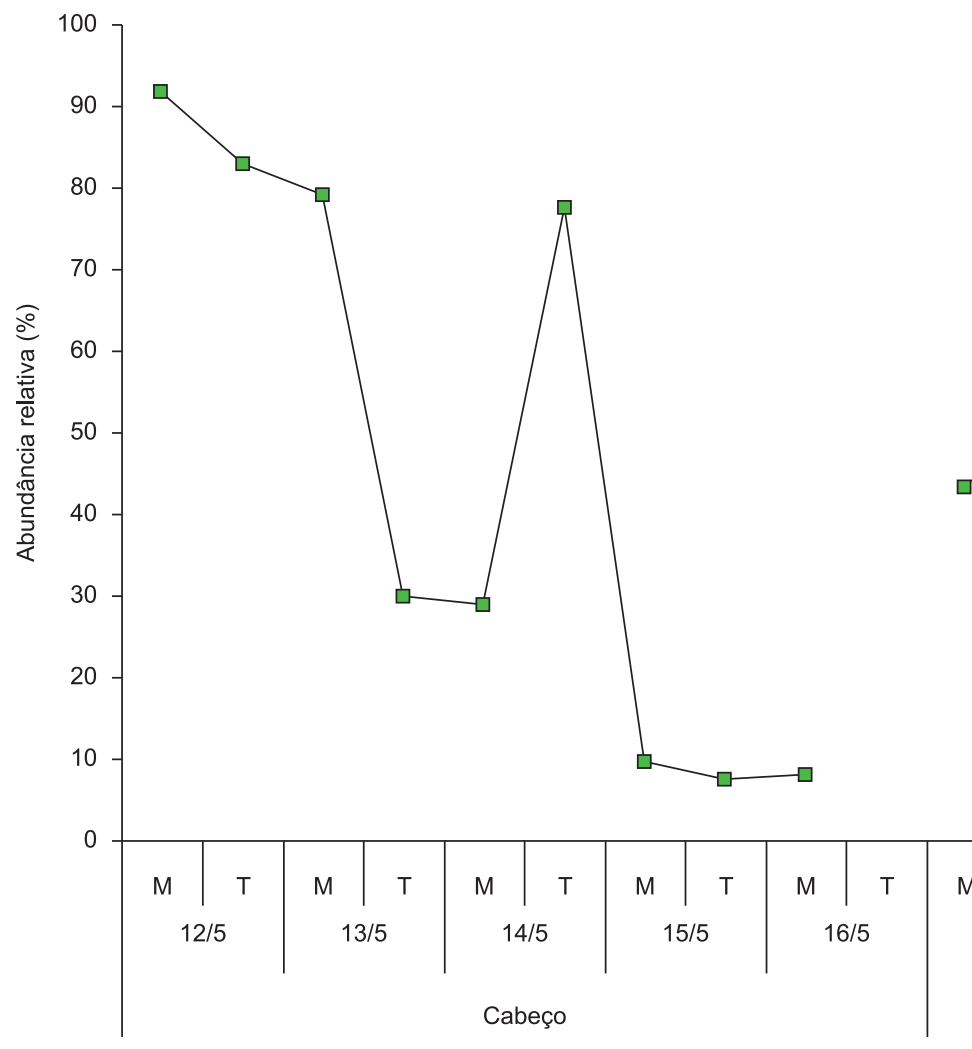

Em riqueza de espécies, as diatomáceas predominam em regiões costeiras e de plataforma, diminuindo gradativamente em direção ao oceano aberto, onde a contribuição de dinoflagelados aumenta significativamente (Fernandes \& Brandini 2004). Já as cianobactérias podem alcançar altas densidades em águas marinhas tropicais, possivelmente constituindo-se como os principais responsáveis pela produtividade primária em casos de escassez de componentes maiores do fitoplâncton (Lalli \& Parsons 1997).

O grupo das diatomáceas foi representativo neste estudo, tendo cerca de $30 \%$ dos táxons registrados, com destaque para Climacosphaenia elongata, Climacosphaenia moniligera, Leptocylindrus danicus e Licmophora ehrenbergii, apesar de ocorrer em menor número que os dinoflagelados, dominantes na área. As diatomáceas dominam e se desenvolvem melhor em águas muito estratificadas.

Mesmo com os grupos dos dinoflagelados e diatomáceas perfazendo o maior número de táxons registrados, houve apenas uma espécie dominante, a cianobactéria Trichodesmium thiebautii. O gênero Trichodesmium primariamente habita a superfície de águas oceânicas oligotróficas, tropicais e subtropicais, e é encontrado em grande abundância nas correntes de oeste, na porção tropical dos giros centrais e em vários mares marginais, representando o principal grupo de organismos planctônicos fixadores de $\mathrm{N}_{2}$ no oceano (Capone et al. 1997, Tyrrel et al. 2003). A dominância de Trichodesmium em águas oligotróficas levanta a questão de como as espécies deste gênero se adaptam a este ambiente. Características deste gênero que parecem contribuir para seu sucesso nos oceanos oligotróficos inclui, além da sua capacidade de fixar $\mathrm{N}_{2}$, seu equilíbrio natural, que o posiciona na parte superior da coluna; um aparato fotossintético adaptado a um regime de alta luminosidade; e uma taxa de crescimento relativamente baixa, a qual, junto com a ausência de pastadores, permite que se mantenha uma alta densidade de indivíduos (Capone et al. 1997).

Figura 3. Abundância relativa da cianofícea Trichodesmium thiebautii na área estudada. $\mathrm{M}=\operatorname{manhã~e~} \mathrm{T}=$ tarde.

Figure 3. Relative abundance of the cyanophyceae Trichodesmium thiebautii at the studied area. $\mathrm{M}=\mathrm{morning}$ and $\mathrm{T}=\mathrm{afternoon}$. 
Segundo Travassos et al. (1999) não são encontradas evidências de ressurgência devido à interação entre as correntes e a topografia no ASPSP, porém foram registradas extensões termohalinas dentro da camada eufótica, sugerindo como causa o atrito entre os fluxos opostos da Corrente Sul Equatorial superficial e a Corrente Subsuperficial Equatorial. No entanto, Araújo \& Cintra (2009) indicam que a interação das correntes com a topografia do ASPSP pode ocasionar processos físicos como a produção de vórtices, perturbações da estrutura termohalina e possíveis mecanismos de ressurgência locais. Este fato pode justificar a ocorrência de maior número de espécies na área desprotegida, no entanto um estudo mais aprofundado, interagindo a comunidade fitoplanctônica com as forçantes físicas, principalmente as correntes, se faz necessário para uma melhor compreensão da dinâmica fitoplanctônica no local.

A coluna d'água desses ambientes é geralmente muito estável, sendo uma zona caracterizada por baixa concentração de nutrientes, águas muito claras e profunda penetração da luz. Esta baixa concentração de nutrientes pode limitar a produção de fitoplâncton, entretanto, nestes casos, é possível que uma espécie bem adaptada às condições locais possa tornar-se dominante ou ainda tal evento pode estar relacionado a uma entrada de sais nutrientes (Siegel 1998). O Nordeste do Brasil é uma das regiões menos produtivas do sistema
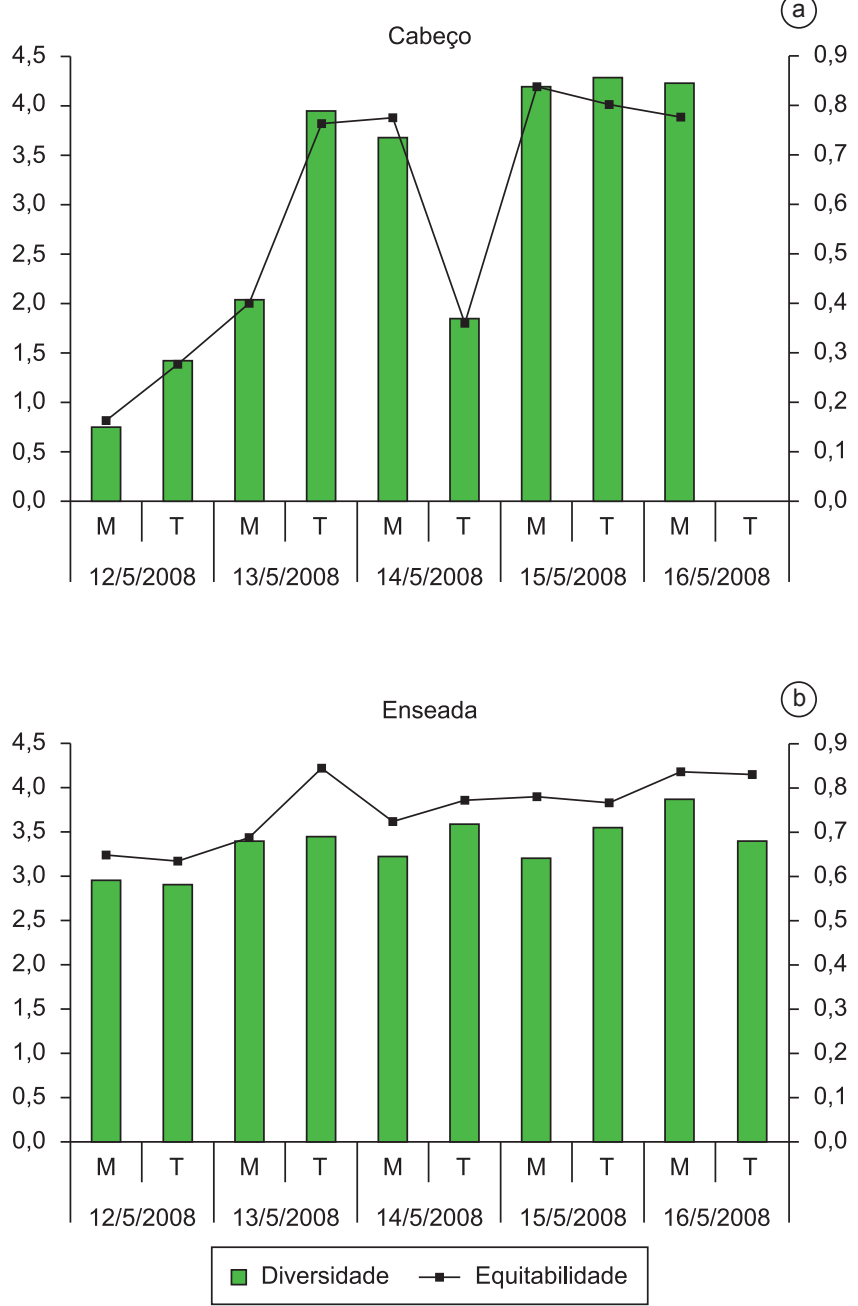

Figura 4. Diversidade e equitabilidade nos locais e períodos de amostragem. $\mathrm{a}=$ Cabeço da tartaruga, $\mathrm{b}=$ Enseada, $\mathrm{M}=$ manhã, $\mathrm{T}=$ tarde.

Figure 4. Diversity and evenness in the sites and periods of sampling. $\mathrm{a}=$ Cabeço da tartaruga, $\mathrm{b}=$ Enseada, $\mathrm{M}=$ morning, $\mathrm{T}=$ afternoon. pelágico brasileiro devido ao impacto das águas oligotróficas da Corrente Sul Equatorial, com a reposição dos nutrientes ocorrendo através da ação dos ventos, divergência de correntes e ressurgência (Ekau \& Knoppers 1999).

Segundo Margalef (1978), um ambiente mais estável implica em um maior grau de organização e complexidade da teia alimentar, com o ambiente apresentando mais nichos, e assim mais espécies. Portanto, era esperado que a estação Enseada apresentasse um maior número de espécies por ser um ambiente mais abrigado e aparentemente mais estável, entretanto, um maior número de táxons foi registrado na estação Cabeço da Tartaruga (117 táxons). Isto pode ser justificado pela presença de três canais entre as ilhas principais, que se comunicam com o ambiente externo (Campos et al. 2010), o que gera um fluxo constante no interior da Enseada, resultando em certa instabilidade do ambiente.

A associação das amostras confirma este fato, evidenciando a diferença entre as comunidades nos pontos de coleta, influenciada principalmente pela dominância de Trichodesmium thiebautii. Em ambas as estações, porém, a comunidade microfitoplanctônica parece estar distribuída homogeneamente ao longo da coluna d'água, devido à forte hidrodinâmica da região.

Além deste fator, a interação entre a Corrente Equatorial Submersa e o ASPSP é capaz de provocar redução de velocidades a montante do mesmo, além de gerar um sistema de vórtices subsuperficiais (50 a $120 \mathrm{~m}$ de profundidade) que se propagam para leste sob o efeito desta corrente. Esses vórtices podem ter um papel importante sobre a dinâmica do plâncton e de nutrientes nas águas adjacentes ao ASPSP, uma vez que essas zonas de fluxo reduzido, associadas à presença de vórtices, proporcionariam um maior tempo de residência dessas águas junto ao ecossistema insular, aumentando a capacidade de retenção de organismos e nutrientes. O número, as dimensões, a frequência de formação e o tempo de duração de tais vórtices são aspectos que influenciariam os processos de enriquecimento do ecossistema insular (Araújo \& Cintra, 2009), o que influenciaria diretamente a produtividade local. Travassos et al. (1999) afirmam, ainda, que mesmo não havendo evidência de ressurgências, a morfologia do fundo marinho e as misturas ocorrentes na coluna de água promovidas por mecanismos locais como divergência de correntes, ventos e interações entre as correntes oceânicas e/ou o relevo submarino exercem um papel importante no processo de intrusão de nutrientes nas camadas superiores da coluna da água, condicionando um incremento na biomassa e produtividade primária local. Na vizinhança de ilhas ou montanhas submarinas que alcançam ou penetram a termoclina pode-se encontrar uma grande concentração de organismos.

No Arquipélago de São Pedro e São Paulo, a diversidade específica e equitabilidade foram altas na quase totalidade das amostras, demonstrando que a comunidade fitoplanctônica está bem distribuída, decrescendo apenas nas amostras onde a espécie Trichodesmium thiebautii foi dominante. Na estação Cabeço, a diversidade e equitabilidade decresceram apenas nas amostras com dominância de Trichodesmium thiebautii. Na Enseada, foram altas em todos os dias e horários, em decorrência da ausência de espécies dominantes. Segundo Omori \& Ikeda (1984), a diversidade específica indica o grau de complexidade da estrutura da comunidade, decrescendo quando a comunidade torna-se dominada por uma ou algumas espécies, quando indivíduos de espécies raras são substituídos por indivíduos de espécies mais comuns, ou quando algumas espécies se reproduzem mais rapidamente.

Alguns dinoflagelados não toleram a alta turbulência e preferem águas estáveis. No entanto, neste estudo o número de táxons foi maior na estação Cabeço, mais exposta e com maior ação dos ventos e correntes, do que na Enseada, área abrigada e, portanto, 


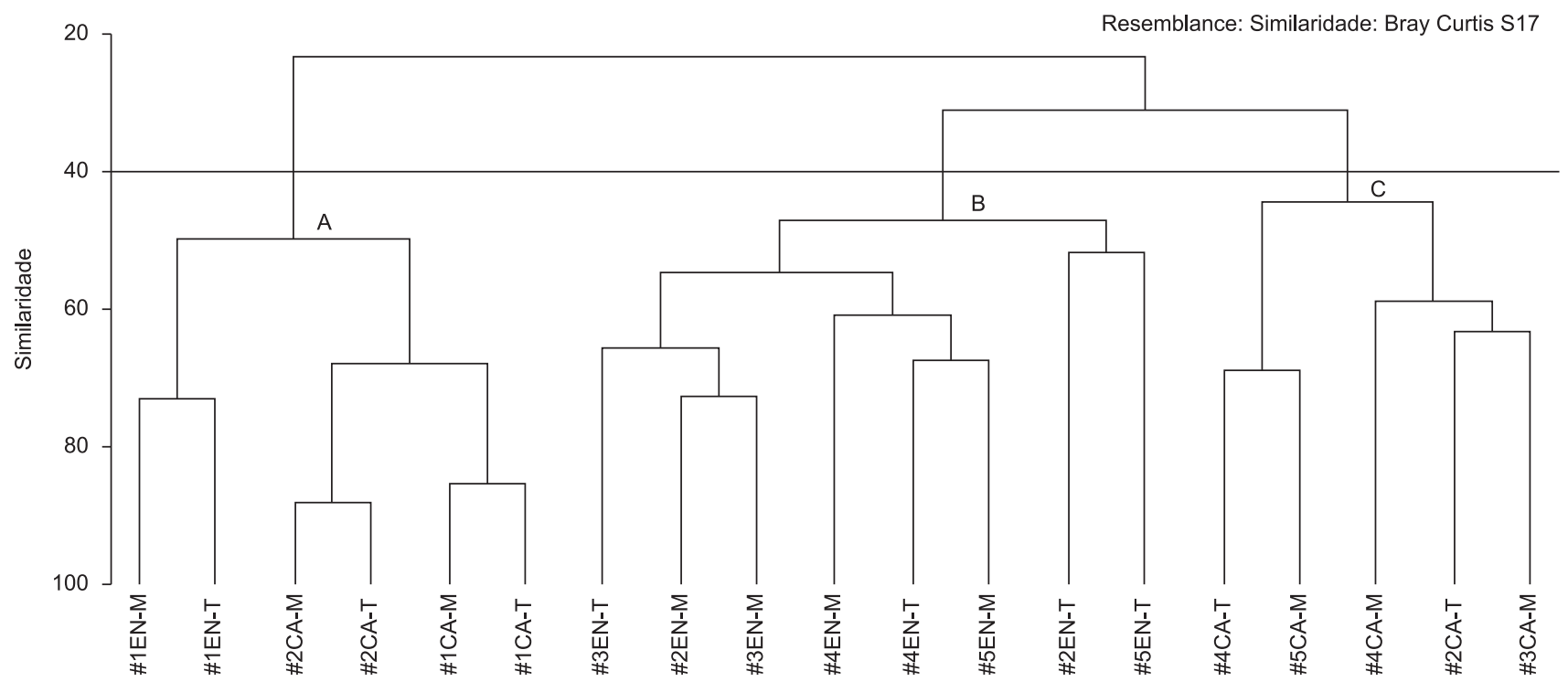

Figura 5. Associação das amostras coletadas na Enseada e no Cabeço da Tartaruga, Arquipélago de São Pedro e São Paulo - NE, Brasil. Coeficiente de Similaridade: Bray-Curtis. \#= dia, $\mathrm{EN}=$ Enseada, $\mathrm{CA}=$ Cabeço da Tartaruga, $\mathrm{M}=$ manhã, $\mathrm{T}=$ tarde.

Figure 5. Association of the samples collected in Enseada and Cabeço da Tartaruga, São Pedro e São Paulo Archipelago - NE, Brazil. Similarity Coefficient: Bray-Curtis. \#= day, EN = Enseada, $\mathrm{CA}=$ Cabeço da Tartaruga, $\mathrm{M}=$ morning, $\mathrm{T}=$ afternoon.

mais estável. A preferência por águas mais estáveis, no entanto, parece ser suplantada pelas condições decorrentes da influência dos ventos e correntes, podendo talvez, estes serem considerados eventos de perturbação, os quais favorecem mudanças na estrutura da comunidade. Segundo Pemberton et al. (2004), os fatores de seleção que levam à dominância de uma ou algumas espécies fitoplanctônicas em qualquer corpo d'água são complexos e envolvem interações de nutrientes, luz, hidrografia, predação e infecção. Em algumas províncias biogeográficas, apenas alguns fatores podem ser a razão primária para o sucesso de uma espécie fitoplanctônica. Mudanças na composição de espécies em águas oligotróficas tendem a estar ligadas a eventos de perturbação.

Dinoflagelados autotróficos e outros flagelados em águas estáveis têm uma vantagem comportamental sobre as diatomáceas e cianofíceas, por serem capazes de nadar para os níveis apropriados de luz. Por outro lado, águas extremamente estáveis tendem a ter uma depleção de nutrientes na zona fótica em decorrência da falta de mistura com as águas profundas ricas em nutrientes, como é o caso da Enseada, com menor número de táxons identificados. Isto irá selecionar uma biota especializada em locais oligotróficos, incluindo espécies de locomoção mais lenta. Assim, os dinoflagelados de natação mais rápida ocupam uma região média, na qual a turbulência é baixa, mas não tão baixa que cause depleção de nutrientes (Levandowsky \& Kaneta 1987).

Em relação a outros grupos, dinoflagelados são responsáveis por $75 \%$ de todas as espécies nocivas do fitoplâncton, com quatro gêneros mais representativos: Alexandrium, Dinophysis, Gymnodinium e Prorocentrum (Smayda \& Reynolds 2002). Dos 131 táxons identificados na área estudada, 18 se destacaram como espécies nocivas. Há espécies que causam apenas colorações inofensivas no corpo d'água, mas sob certas condições podem ocasionar a morte de peixes e invertebrados devido à depleção do oxigênio, como por exemplo, a espécie de dinoflagelado Gonyaulax polygramma Stein. Além disso, podem produzir potentes toxinas capazes de afetar toda a cadeia alimentar, inclusive o Homem, causando uma variedade de problemas neurológicos e gastrintestinais. As espécies Ceratium fusus (Ehrenberg) Dujardin, Gonyaulax polygramma, Lingulodinium polyedra (Stein) Dodge, Pyrophacus horologium Stein, Pyrophacus steinii (Schiller)
Wall \& Dale e Protoperidinium latispinum Mangin podem causar a Paralytic Shellfish Poisoning (PSP). Phalacroma rotundatum (Claparèd \& Lechmann) Kofoid \& Michener pode provocar a Diarrhetic Shellfish Poisoning (DSP). Dinoflagelados do gênero Prorocentrum podem causar o Ciguatera Fish Poisoning, entre outras (Hallegraeff et al. 1995, Food... 2004). Segundo Procopiak et al. (2006), as diatomáceas Coscinodiscus centralis Ehrenberg, Cylindrotheca closterium (Ehrenberg) Reimann \& J.C.Lewin e Leptocylindrus danicus são consideradas potencialmente nocivas, porém não tóxicas.

Várias das espécies identificadas são referidas como indicadoras de águas da Corrente do Brasil, originada a partir da bifurcação da CorrenteSul Equatorial, como é o caso de Ceratium candelabrum var. candelabrum (Ehrenberg) Stein, Ceratium contortum var. contortum (Gourret) Cleve, Ceratium declinatum var. declinatum, Ceratium extensum (Gourret) Cleve, Ceratium geniculatum (Lemmermman) Cleve, Ceratium gibberum Gourret, Ceratium hexacanthum Gourret, Ceratium horridum var. molle (Kofoid) Jörgensen, Ceratium longirostrum Gourret, Ceratium lunula (Schimper) Jörgensen, Ceratium massiliense var. massiliense Sournia, Ceratium paradoxides Cleve, Ceratium pentagonum var. tenerum, Ceratium strictum (Kofoid) E.G.Jørgensen, Ceratium symmetricum var. symmetricum Graham \& Bronikowsky, Ceratium teres, Corythodinium tesselatum (Stein) Loeblich Jr. \& Loeblich III, Goniodoma polyedricum, Lingulodinium polyedrum (Stein) Dodge, Ornithocercus magnificus Stein, Ornithocercus quadratus Schütt, Ornithocercus steinii Schütt, Phalacroma argus, Phalacroma cuneus Schütt, Phalacroma doryphorum, Podolampas bipes Stein, Podolampas elegans Schütt, Pyrophacus steinii (Schiller) Wall \& Dale (Balech 1988).

A comunidade fitoplanctônica está caracterizada por uma maior diversidade de dinoflagelados e dominância de Trichodesmium thiebautii, indicando uma composição florística de ambiente estável, de águas transparentes e oligotróficas.

\section{Agradecimentos}

Os autores agradecem ao Conselho Nacional de Desenvolvimento Científico e Tecnológico - CNPq, pelo auxílio financeiro ao projeto (Processo n ${ }^{\circ}$ 558469/2005-1). 


\section{Referências Bibliográficas}

ALGAEBASE. http://www.algaebase.org/ (último acesso em 13/12/2010).

ARAÚJO, M. \& CINTRA, M. 2009. Modelagem matemática da circulação oceânica na região equatorial do Arquipélago de São Pedro e São Paulo. In O arquipélago de São Pedro e São Paulo: 10 anos de estação científica (D.L. Viana, F.H.V. Hazin \& M.A.C. Souza, orgs). SECIR, Brasília, p.106-113.

AYRES, M., AYRES JÚNIOR, M., AYRES, D.L. \& SANTOS, A.A. 2007. BioEstat 5.0: Aplicações estatísticas nas áreas das ciências bio-médicas. Ong Mamirauá, Belém.

BALECH, E. 1988. Los Dinoflagelados del Atlantico Sudoccidental. Instituto Español de Oceanografia, Madrid. (Publicaciones especiales, n. 1).

BRANDINI, F.P. \& MORAES, C.L.B. 1986. Composição e distribuição do fitoplâncton em áreas costeiras e oceânicas da região Sueste do Brasil. Nerítica. 1(3):9-19.

BRÖCKEL, K. \& MEYERHÖFER, M. 1999. Impact of the rocks of São Pedro and São Paulo upon the quantity and quality of suspended particulate organic matter. Arch. Fish. Mar. Res. 47(2-3):223-238.

CAMPOS, T.F.C., BEZERRA, F.H.R., SRIVASTAVA, N.K., VIEIRA, M.M. \& VITA-FINZI, C. 2010. Holocene tectonic uplift of the St. Peter and St. Paul Rocks (Equatorial Atlantic) consistent with emplacement by extrusion. Mar. Geol. 271:177-181. http://dx.doi.org/10.1016/j. margeo.2010.02.013

CAPONE, D.G., ZEHR, J.P., PAERL, H.W., BERGMAN, B. \& CARPENTER, E.J. 1997. Trichodesmium, a globally significant marine cyanobacterium. Science. 276:1221-1229. http://dx.doi.org/10.1126/ science. 276.5316 .1221

CUPP, E.E. 1943. Marine plankton diatoms of the West Coast of North America. Bull. Scripps Inst. Oceanogr. Univ. Calif. 5: 1-237.

DESIKACHARY, T.V. 1959. Cyanophyta. Indian Council of Agricultural Research, New Delhi.

DODGE, J.D. \& MARSHALL, H.G. 1994. Biogeographic analysis of the armored planktonic dinoflagellate Ceratium in the North Atlantic and adjacent seas. J. Phycol. 30:905-922. http://dx.doi.org/10.1111/j.00223646.1994.00905.x

EKAU, W. \& KNOPPERS, B.A. 1999. An introduction to the pelagic system of the northeast and east brazilian shelf. Arch. Fish. Mar. Res. 47(2):113-132.

ESKINAZI-LEÇA, E. \& PASSAVANTE, J.Z.O. 1972. Estudo da plataforma continental na área do Recife (Brasil) IV. Aspectos quantitativos do fitoplâncton. Trab. Oceanog. Univ. Fed. PE. 13:83-106.

ESKINAZI-LEÇA, E., MOURA, A.N., SILVA-CUNHA, M.G.G. \& KOENING, M.L. 2002. Microalgas marinhas do estado de Pernambuco: diagnóstico da biodiversidade de Pernambuco. In Diagnóstico da biodiversidade de Pernambuco (M. Tabarelli \& J.M.C. Silva, org.). Secretaria de Ciência Tecnologia e Meio Ambiente/Editora Massangana, Recife, v. 1, p.79-96.

FOOD AND AGRICULTURE ORGANIZATION - FAO. 2004. Marine biotoxins. FAO food and nutrition papers. FAO, Rome.

FERNANDES, L.F. \& BRANDINI, F.P. 2004. Diatom associations in shelf waters off Parana State, Southern Brazil: annual variation in relation to environmental factors. Braz. J. Oceanogr. 52(1):19-34.

GAETA, A.S., LORENZETTI, J.A., MIRANDA, L.B., SUSINI-RIBEIRO, S.M.M., POMPEU, M. \& ARAÚJO, C.E.S. 1999. The Victoria Eddy and its relation to the phytoplankton biomass and primary productivity during the austral fall of 1995. Arch. Fish. Mar. Res. 47(2/3):253-270.

GALVÃO, I.B. 2000. O nanoplâncton e o microplâncton da Zona Econômica Exclusiva do Nordeste do Brasil (REVIZEE - NEII). Dissertação de mestrado, Universidade Federal de Pernambuco, Recife.

GÓMEZ, F. 2005. A list of free-living dinoflagellate species in the world's oceans. Acta Bot. Croat. 64(1):129-212.

GROSS, M.G \& GROSS, E. 1996. Oceanography a view of earth. Prentice Hall, New Jersey.
HALLEGRAEFF, G.M., ANDERSON, D.M. \& CEMBELLA, A.D. 1995. Manual on harmful marine microalgae. UNESCO. (IOC Manuals and Guides UNESCO, n.33).

HUSTEDT, F. 1930. Die Kieselalgen: Deutschlands, Österreichs und der Schweiz unter Berücksichtigung der übringen Länder Europas sowie der angrenzenden Meeresgebiete. In Kryptogamen-Flora von Deutstschland, Österreich und der Schweiz (L. Rabenhorst). Akademische Verlagsgesellschaft Geest \& Portig K. G., Leipzig, v.7, pt.1.

HUSTEDT, F. 1959. Die Kieselalgen: Deutschlands, Österreichs und der Schweiz unter Berücksichtigung der übringen Länder Europas sowie der angrenzenden Meeresgebiete. In Kryptogamen-Flora von Deutstschland, Österreich und der Schweiz (L. Rabenhorst). Akademische Verlagsgesellschaft Geest \& Portig K. G., Leipzig, 7(1-6), pt.2.

HUSTEDT, F. 1961. Die Kieselalgen: Deutschlands, Österreichs und der Schweiz unter Berücksichtigung der übringen Länder Europas sowie der angrenzenden Meeresgebiete. In Kryptogamen-Flora von Deutstschland, Österreich und der Schweiz (L. Rabenhorst). Akademische Verlagsgesellschaft Geest \& Portig K. G., Leipzig, 7(1-4), pt.3.

KOENING, M.L \& LIRA, C.G., 2005. O gênero Ceratium Schrank (Dinophyta) na plataforma continental e águas oceânicas do estado de Pernambuco, Brasil. Acta Bot. Bras. 19(2):391-397. http://dx.doi. org/10.1590/S0102-33062005000200022

KOENING, M.L. \& MACÊDO, S.J. 1999. Hydrology and phytoplankton community structure at Itamaracá-Pernambuco (Northeast Brazil). Braz. Arch. Biol. Technol. 42(2):381-392.

KOENING, M.L. \& OLIVEIRA, M.S. 2009. Estrutura da comunidade fitoplanctônica. In O arquipélago de São Pedro e São Paulo: 10 anos de estação científica (D.L. Viana, F.H.V. Hazin \& M.A.C Souza, orgs.). SECIR, Brasília, p.116-123

KOENING, M.L., WANDERLEY, B.E. \& MACÊDO, S.J. 2009. Microphytoplankton structure from the neritic and oceanic regions of Pernambuco State - Brazil. Braz. J. Biol. 69(4):1037-1046. http://dx.doi. org/10.1590/S1519-69842009000500007

LALLI, C.M. \& PARSONS, T.R. 1997. Biological Oceanography: an introduction. 2nd ed. Butterworth Heinemann, Oxford.

LEVANDOWSKY, M. \& KANETA, P. 1987. Behaviour in dinoflagellates. In The Biology of Dinoflagellates (F.J.R. Taylor). Balckwell Scientific Publications, London, p.360-397.

LiCEA, L., MORENO, J.L., SANTOYO, H. \& FigueROA, G. 1995. Dinoflagelados del Golfo de California. Universidad Autonoma de Baja California Sur, Califórnia.

LOBO, E. \& LEIGHTON, G. 1986. Estructuras comunitarias de las fitocenosis planctonicas de los sistemas de desembocaduras de rios y esteros de la zona central de Chile. Rev. Biol. Mar. 22(1):1-29.

LONGHURST, A.R. \& PAULY, D. 2007. Ecologia dos oceanos tropicais. EDUSP, São Paulo.

MACEDO-SAIDAH, F.E. \& MOREIRA-FILHO, H. 1977. Composição e distribuição do microfitoplâncton nas águas do Atlântico Leste do Brasil. Publ. Inst. Pesqui. Mar. Rio J. 107:1-12.

MAFALDA JÚNIOR, P.O., MOURA, G.F., MELO, G.S., SAMPAIO, J.A.A., FEITOSA, F.A.N., PASSAVANTE, J.Z., MOREIRA, O.P. \& SOUZA, C.S. 2009. Biomassa fitoplanctônica na ZEE da região Nordeste do Brasil. In Programa Revizee - Score Nordeste (F.H.V. Hazin). Editora Martins \& Cordeiro, Fortaleza, p.11-26.

MARGALEF, R. 1978. Life-forms of phytoplankton as survival alternatives in an unstable environment. Oceanol. Acta. 1(4):493-509.

MEDEIROS, C., MACEDO, S.J., FEITOSA, F.A.N. \& KOENING, M.L. 1999. Hydrography and phytoplankton biomass and abundance of North-East Brazilian waters. Arch. Fish. Mar. Res. 47(2/3):133-151.

MÜLLER-MELCHERS, F.C. 1955. Las diatomeas del plancton marino de las costas del Brasil. Bol. Inst. Ocean. Univ. S. Paulo 6(1-2):93-138.

OMORI, M. \& IKEDA, T. 1984. Methods in marine zooplankton ecology. J. Wiley, New York. 
PASSAVANTE, J.Z.O. 1979. Contribuição ao estudo dos dinoflagelados da Plataforma Continental de Pernambuco- Brasil. Trab. Oceanog. Univ. Fed. PE. 14:31-54.

PEMBERTON, K., REES, A.P., MILLER, P.I., RAINE, R. \& JOINT, I. 2004 The influence of water body characteristics on phytoplankton diversity and production in the Celtic Sea. Cont. Shelf Res. 24:2011-2028. http://dx.doi.org/10.1016/j.csr.2004.07.003

PÉRAGALLO, H. \& PÉRAGALLO, M. 1897-1908. Diatomées marines de France et des districtes maritimes voisins. M.J. Tempère, Paris.

PIELOU, E.C. 1977. Mathematical ecology. Wiley, New York.

PORTO, M.A.C. 2006. Arquipélago de São Pedro e São Paulo. In O mar no espaço geográfico brasileiro (C.F.S Serafim., org). Ministério da Educação, Secretaria de Educação Básica, Brasília, p.74-80.

PROCOPIAK, L.K., FERNANDES, L.F. \& MOREIRA-FILHO, H. 2006 Diatomáceas (Bacillariophyta) marinhas e estuarinas do Paraná, Sul do Brasil: lista de espécies com ênfase em espécies nocivas. Biota Neotrop. 6(3): http://www.biotaneotropica.org.br/v6n3/pt/abstract?inventory+ bn02306032006. (último acesso em 20/07/2010).

RICKLEFS, R.E. 2003. Economia da natureza. 5nd ed. Guanabara Koogan, Rio de Janeiro.

SIEGEL, D.A. 1998. Resource competition in a discrete environment: Why are plankton distributions paradoxical? Limnol. Oceanogr. 43(6):1133-1146. http://dx.doi.org/10.4319/lo.1998.43.6.1133

SILVA-CUNHA, M.G.G. \& ESKINAZI-LEÇA, E. 1990. Catálogo das diatomáceas (Bacillariophyceae) da plataforma continental de Pernambuco. SUDENE, Recife.
SMAYDA, T.J. \& REYNOLDS, C.S. 2002. Strategies of marine dinoflagellate survival and some rules of assembly. J.Sea Res. 49:95-106. http://dx.doi. org/10.1016/S1385-1101(02)00219-8

SUSINI-RIBEIRO, S.M.M. 1999. Biomass distribution of pico, nano and micro-phytoplankton on the continental shelf of Abrolhos, East Brazil. Arch. Fish. Mar. Res. 47(2-3):271-284.

TAYLOR, F.J.R. 1987. Ecology of dinoflagellates: A. General and marine ecosystems. In The Biology of Dinoflagellates (F.J.R. Taylor). Balckwell Scientific Publications, London, p.398-502.

TENENBAUM, D.R. 2006. Dinoflagelados e tintinídeos da região central da Zona Econômica Exclusiva brasileira: guia de identificação. Museu Nacional, Rio de Janeiro.

TENENBAUM, D.R., GOMES, E.A.T. \& GUIMARÃES, G.P. 2007. Microorganismos planctônicos: pico, nano e micro. In Características hidrobiológicas da região central da Zona Econômica Exclusiva brasileira (Salvador, BA, ao Cabo de São Tomé, RJ (J.L. VALENTIN, org.). Ideal Gráfica e Editora, Brasília, v.1, p.83-124.

TOMAS, C.R. 1997. Identifying marine phytoplankton. Academic Press, San Diego.

TRAVASSOS, P., HAZIN, F.H.V., ZAGAGLIA, J.R., ADVINCULA, R. \& SCHOBER, J. 1999. Thermohaline structure around seamounts and islands off North-Eastern Brazil. Arch. Fish. Mar. Res. 47(2-3):211-222.

TYRREL, T., MARAÑÓN, E., POULTON, A.J., BOWIE, A.R., HARBOUR, D.S. \& WOODWARD, E. M.S. 2003. Large-scale latitudinal distribution of Trichodesmium spp. in the Atlantic Ocean. J. Plankton Res. 25(4):405-416. http://dx.doi.org/10.1093/plankt/25.4.405

YONEDA, N.T. 1999. Área Temática: Plâncton. Centro de Estudos do Mar, Universidade Federal do Paraná. 